\title{
Journal for the Study of Postsecondary and Tertiary Education
}

Volume 3, 2018

\section{AN EXAMINATION OF ACADEMIC SELF-ESTEEM IN Historically BLACK COLLEGE/UNIVERSITY (HBCU) STUdents: CONSIDERING ACADEMIC PERFORMANCE AND TASK DIFFICULTY}

Novell E. Tani*

Akeem T. Ray

* Corresponding author
Florida Agricultural \& Mechanical University, Tallahassee FL, USA

Florida Agricultural \& Mechanical University, Tallahassee FL, USA
Novell.Tani@,famu.edu

Akeem1.Ray@famu.edu

\section{ABSTRACT}

Aim/Purpose

Using a sample of historically Black college/university (HBCU) students, the study examined (1) differences in academic self-esteem (ASE) levels when considering students' performance on an academic task that was either easy (low in cognitive demand) or difficult (high in cognitive demand), (2) gender differences in ASE levels, and (3) variations in academic self-concepts, given baseline general self-esteem levels, GPA, academic performance (AP), and perceptions of task difficulty.

Background This study is the first to date which examines African American students' ASE differences as a result of academic performance and perceptions of task rigor. The optimal arousal theory serves as a framework for the study design; the study utilized a manipulation of the cognitive demand task condition as a means of investigating ASE. Given the mixed and limited literature on gender differences in African American/HBCU subjects, gender differences were explored.

Methodology Quantitative analyses of systematically-built surveys and assessments allowed for the examination of participants ( $n=410$ HBCU student; 303 females). Correlations, analyses of variance, and regression analyses were completed to address research aims.

Contribution A novel approach to examining ASE variants within African American students matriculating through an HBCU context is provided.

Accepted as an research article by Editor Crystal R. Chambers. | Received: May 28, 2018 | Revised: August 20, August 25, September 27, 2018 | Accepted: September 28, 2018.

Cite as: Tani, N. E., \& Ray, A. T. (2018). An examination of academic self-esteem in historically black college/university (HBCU) students: Considering academic performance and task difficulty. Journal for the Study of Postsecondary and Tertiary Education, 3, 97-116. https://doi.org/10.28945/4130

(CC BY-NC 4.0) This article is licensed to you under a Creative Commons Attribution-NonCommercial 4.0 International License. When you copy and redistribute this paper in full or in part, you need to provide proper attribution to it to ensure that others can later locate this work (and to ensure that others do not accuse you of plagiarism). You may (and we encourage you to) adapt, remix, transform, and build upon the material for any non-commercial purposes. This license does not permit you to use this material for commercial purposes. 
Findings Students in the Low Cognitive Demand task condition displayed significantly higher levels of academic self-esteem (ASE) than High Cognitive Demand task participants; males yielded marginally higher academic self-esteem levels than females $(M=54.21, M=51.58 ; \mathrm{p}=.04)$; and while academic performance marginally predicted ASE levels, most of the variance was attributed to baseline self-esteem levels and subjects' perceptions of task rigor.

Recommendations Educational stakeholders, namely, teachers and administrators, are advised to for Practitioners contemplate the importance of students' perceptions of task difficulty and feasibility and the possible impacts on academic self-concepts. Additionally, educators may consider students' initial self-concepts when deciding how and when to provide feedback on academic performance.

Recommendation Self-esteem levels are likely to vary as a result of other self-concepts (e.g., motifor Researchers vational, personal, and contextual factors) that were not examined. As such, the study findings provide clarity on varying ASE levels within the specific sample and should be taken with care.

Impact on Society Increasing our understanding of what negatively or positively impacts academic self-esteem levels in students will further aid our ability to foster stronger scholastic self-concepts in the generations to come.

Future Research Future research should examine ASE levels and the extent that perceptions of task rigor impact varying self-esteem levels in African American students enrolled at more racially-heterogenous higher educational contexts (e.g., primarily White institutions, Hispanic serving institutions).

Keywords academic self-esteem, perceptions of rigor, academic achievement, HBCU, college students

\section{INTRODUCTION}

Academic success following high school can be gauged in one of two fashions: academic achievement (e.g., grade point averages (GPA), test scores, enrollment, and employment) or academic attainment (e.g., graduation rates, retention, completion, and persistence). The present study focuses on GPA as a measure of academic performance; however, it must be noted that extant literature has established a link between the academic achievement and attainment (Gershenfeld, Hood, \& Zhan, 2015). Underrepresented (African American) students' first-semester GPA proved to impact 6-year graduation rates. According to reports provided by the National Center for Educational Statistics (NCES, 2017), approximately $40 \%$ of college students graduate within 4-years of starting college. Roughly $20 \%$ of African American students that began college in 2009 finished within a 4-year time span; whereas the completion rates of their Asian American (50\%), European Americans (White; $44 \%$ ), and Hispanic (30\%) peers differ significantly. Additionally, women accounted for a large portion of the graduates; in comparison to $16 \%$ of Black men, $24 \%$ of Black women completed college within four years (NCES, 2017). Analyzing empirical literature spanning 13 years, researchers discerned Black men as demonstrating the lowest level of academic performance and completion internationally (Voyer \& Voyer, 2014). As postsecondary and tertiary-leveled educators, instructors strive to foster learning environments that allow for egalitarianism; however, the research far too often highlights academic achievement gaps. Often studies report European Americans' academic performance levels as being higher than their counterparts of other ethnic backgrounds (Brayfield, Adler, \& Zablotsky, 1990; Dollinger \& Clark, 2012; NCES, 2017; Steele-Johnson \& Leas, 2013).

While academic performance and academic success are focal points of educators in educational institutions, the mental and emotional states of students are also highly regarded. Educators must contin- 
ually consider the psycho-social components that relate to academic performance. Self-esteem entails an individual's attitude toward self, personal beliefs of self-worth, and personal feelings relative to levels of respect deserved from self and others (von Soest, Wichstrøm, \& Kvalem, 2016). The SelfEsteem Model by Van Laar (2000) posits that African American college students with low academic performance develop attributes regarding academic failures that lend themselves to self-defeating internalized self-concepts. Researchers have examined the degrees to which self-esteem influences academic performance (Davis-Kean \& Sandler, 2001; DeFreitas, 2012; Hoffman, Knight, \& Wallach, 2007; Kling, Hyde, Showers, \& Buswell, 1999; Okech \& Chambers, 2012). Self-esteem and a dynamic learning environment positively predict academic performance (Hoffman et al., 2007). However, based on our review of the literature, there exists no study to date which examines the extent to which students' self-esteem varies because of academic performance feedback and perceptions of task rigor. Ask yourself as an educator, teaching emerging adults of color, "Is it not equally important that researchers examine the extent to which academic performance influences students' selfesteem levels?"

In 2004, Oates presented a longitudinal study that assessed the impact of attending high schools and colleges with higher African American enrollment and the effects on self-esteem and self-efficacy. When controlling for pre-collegiate factors, such as school demographical makeup, African American students displayed enhanced levels of self-esteem in schools comprised of higher Black enrollment (Oates, 2004). Oates indicated that, while factors like socioeconomic status and indicators of achievement impacted dimensions of self-concept, students' placement in a college context with a higher populated African American student body had the greatest influence on African American students' self-esteem (Oates, 2004). To this end, findings establish a significant and positive relationship between African American students' self-esteem and the number of students of color at an institution.

The present study allows for an analysis of African American subjects matriculating through a predominantly Black institution, thus less likely to experience racial stereotypes that students of color face when progressing through a Predominantly White Institution (PWI) (Fries-Britt \& Turner, 2001). While the present study does not assess stereotype threat, it does examine subjects' perceptions of task rigor. This index of perceived difficulty offers a gauge of testing anxiety that may mediate the extent to which academic performance influences academic self-esteem (Tempel \& Neumann, 2014). The present study is unique in that it offers a novel analysis of self-esteem variations when considering a sample of African American/Black college students distinctively seated in a learning environment which optimally lends itself to the development of positive self-concepts and academic success within students of color (Cokley, 2000, 2002; Oates, 2004) - a Historically Black College/University (HBCU). Finally, this paper provides an analysis of students' state-self-esteem when presented with performance feedback (see Harter \& Whitesell, 2003 for additional literature on trait vs. state esteem).

\section{LITERATURE REVIEW}

\section{GENERAL SELF-ESTEEM (GSE)}

A self-concept targets a particular element of one's self (i.e., social, emotional, academic, and physical (Kling et al., 1999; Vispoel, 1995). Researchers examine self-esteem, a self-concept where specific views of the self, be it physical, social, or personality-based self-imagery, reflect an overall sense of personal value. General self-esteem (GSE) is defined as the global attitude towards self, satisfaction with self, and one's perceived worth when comparing self to others (Davis-Kean \& Sandler, 2001). There is sparse literature surrounding self-esteem levels in African American, college-aged samples (Chapell \& Overton, 2002). Meta-analyses findings stress that correlations and effect sizes range from very weak to strong values when exploring relationships between GSE and demographic factors such as race, culture, socioeconomic status, age, personal experiences, and academic perfor- 
mance (Davis-Kearn \& Sandler, 2001; Kling et al., 1999). Gray-Little and Hafdahl's (2000) metaanalysis provides a thorough review of factors that impact differences in self-esteem. Findings across the literature report higher self-esteem levels in African Americans (Black) than European Americans (White). This trend is rationalized by varying the response styles of African Americans, a group-byitem interaction favoring Black respondents, or defensive responding. Here too findings highlight variations in self-esteem levels by way of race across factors of age, racial identity levels, socioeconomic factors, etc. (Gray-Little \& Hafdahl, 2000).

In a cross-sectional analysis of African American students, Chapell and Overton (2002) found selfesteem and grades strongly related in $6^{\text {th }}$ grade and college-aged students. The same association was not observed in $10^{\text {th }}$ and $12^{\text {th }}$ graders. While the middle and high school participants were drawn from public schools populated almost entirely by African American students, only $10 \%$ of the students that attended the public university were Black (Chapell \& Overton, 2002; Cokley, 2000, 2002). Extant literature has established associations between HBCU students' general self-esteem levels to academic performance $(r=.315, p<.1)$ (Lockett \& Harrell, 2003) and provides evidence of a bidirectional causal link (Lockett \& Harrell, 2003; Stupnisky et al., 2007); however, researchers have yet to examine neither variances in self-esteem or academic, domain-specific esteem by means of actual higher or lower academic performance, performance feedback, nor students' perceptions of anxiety (e.g., task rigor).

\section{Gender differences in self-esteem}

Numerous of studies have provided evidence of gender difference in scholastic achievement (see Voyer \& Voyer, 2014). Baker (2015) found social support to impact African American college students' academic performance (GPA) differently by gender, while Buddington and Haydel (2015) provide evidence that factors like emotional well-being and gendered-self-concepts (e.g., "maleness") predict HBCU students' academic achievement in different ways. Moreover, given the graduation rates provided in the opening and considering the fact that the percentage of women enrolled at HBCUs positively predict graduation rates among HBCU students (Cheng, Suwanakul, \& Wu, 2015), the sample used for the present study distinctively allows for further investigation of possible gender differences in academic-based self-esteem. While self-appraisal levels have been found to differ across demographics (Davis-Kean \& Sandler, 2001; Mackinnon, Smith, \& Carter-Rogers, 2015; Pullman \& Allik, 2008), extant literature notes that girls commonly display lower general self-esteem than boys (Kling et al., 1999; Josephs, Tafarodi, \& Markus, 1992; von Soest et al., 2016). Kling and colleagues' (1999) meta-analysis, reviewing over 200 studies, found mean effect sizes which mirrored trends denoting lower levels of self-esteem in female participants in comparison to male participants. The study revealed a small overall gender effect size of $=0.21$ and the authors noted gender roles as a possible source of observed gender differences in self-esteem (Kling et al., 1999). Additionally, newer research on self-actualization mirrors these finding (Okech \& Chambers, 2012).

Since women make up approximately $60 \%$ of HBCUs demographics, researchers must examine psycho-emotional factors that may relate to African Americans' performance when matriculating through a relatively homogenous educational environment. Of the studies that have examined gender differences of self-esteem within African American/Black college students in the U.S., very few have sought to or been able to investigate gender differences due to small male sample sizes (e.g., Chapell \& Overton, 2002; Hope, Chavous, Jagers, \& Sellers, 2013; Lockett \& Harrell, 2003). A newer study conducted by Sprecher, Brooks, and Avogo (2013) found different levels of self-esteem across racial and gendered social groups. Results indicated men as having higher self-esteem than women. Results also specified negligible gender differences in self-esteem among Black students; in comparison to the larger sample, Black women students reported higher self-esteem than Black men. The subsample of Black students displayed significantly higher self-esteem scores than the White subsample, Hispanic subsample, and Asian subsample (Sprecher et al., 2013). 
Considering the literature discussed, current studies findings do not lend themselves to answering the question "How is self-esteem likely to vary between African American men and women attending a historically black college?" Being able to capture possible gender differences in the academic, domain-specific area of self-esteem allows the present study to address a longstanding gap that exists within higher education research. Understanding gender differences in self-esteem, considering the broader context of higher learning and given the academic performance differences that may exist when comparing men and women from different demographic backgrounds, particularly at HBCUs, remains paramount for understanding the role of the intersections of race, gender, and academic performance.

\section{ACADEMIC PERFORMANCE (AP)}

Academic performance is indicative of one's ability to perform on cognitive task $(\mathrm{s})$ and reach certain academic goals. Several studies note self-esteem as relating to academic performance (Gebauer et al., 2015; Josephs et al., 1992; Kling et al., 1999; von Soest et al., 2016). Minoritized students, namely African American students, experience reduced self-esteem and lower levels of academic performance when experiencing scenarios of stereotypes, stereotype threat, and negative generalizations (Steele \& Aronson, 1995; Tempel \& Neumann, 2014; Thames et al., 2014). Examining African American (AA) $(n=45)$ and European American college students $(n=47)$, Thames and colleagues (2014) found stereotype threat, perceived discrimination, and examiner race to negatively influence neuropsychological performances (NP) and cognitive performances (e.g., memory) in African American students more so than European American students. However, African American students are reportedly more likely to view their academic outcomes as based on preexisting knowledge or skill (e.g., to make internal attributions), more so than their White counterpart (Aruguete \& Hardy, 2016). These findings underscore the importance of contextual factors, namely institutional demographics, and cognitive-based outcomes. They also suggest a need to examine further the degree that external attributions influence self-esteem.

There exists an adaptive connection between achievement over time, students' self-esteem levels, and academic achievement profiles. In a study which examined African American, freshman college students attending three large PWIs $(n=324)$, Hope and colleagues (2013) found links between students' general self-esteem, academic achievement (GPA), and academic identification profiles. Students with higher high school grade point averages yielded higher self-esteem levels; those lower high school GPAs showed significantly lower levels of self-esteem. Students' initial academic contingencies of self-worth, or the extent to which they felt their self-esteem varied by actual achievement, moderately correlated with end of year college academic performance (GPA). However, concepts of academic worth captured at the end of the school year did not prove to associate with actual collegiate performance. There continued to be a negative association between general self-esteem and academic contingencies of self-worth (Hope et al., 2013). While students' initial self-esteem levels did not relate to cumulative freshman GPA, end of year self-esteem proved to be positively associated. Variations in students' academic identification clusters (self-esteem by performance) varied based on levels of anxiety, perceived stress, and other psychological symptoms observed (Hope et al., 2013).

\section{BAROMETRIC ACADEMIC SELF-ESTEEM (ASE)}

Studies have established that African American college students tend to hold higher academic selfconcept and self-esteem levels depending on the racial/ethnic composition of their institution (Cokley 2000, 2002; Oates, 2004), with higher self-concepts observed when students attend schools with a high population of students of color. Yet, academic self-esteem (ASE) is one's evaluation of how he/she feels about one's cognitive abilities and academic performance. ASE is also defined as "one's attitudes towards the learning process, a sense of direction, and self-expectations for academic performance" (Lipnevich, 2006). According to Kernis, Grannemann, and Barclay (1989), barometric self-esteem is defined as rapid, short-term fluctuations of self-esteem; the present study seeks to ex- 
amine barometric academic self-esteem - defined as short-term fluctuations of ASE. Literature examining adolescent students' state academic self-esteem levels show variations based on real-time feedback on graded assignments (Hartner \& Whiteesell, 2003); however, there exists no such literature for Black students at HBCUs. Academic self-esteem is often measured using general self-esteem instruments that have been revised to incorporate new measures of academic self-esteem. Examples of these tests include the revised Feelings of Inadequacy Scale (Janis \& Field, 1959) and the Rosenberg Self-esteem Scale (Rosenberg, 1965). Scales possess items where participants respond to academic/cognitive based questions such as, "Are your skills weaker than other people in this class?" and "Do you believe you are as smart as most people?" (Rosenberg, 1965). These differ from the Academic self-concept scales that are typically used to cover a larger gambit of academic-based selfconcepts (e.g., efficacy, confidence, school-satisfaction, and self-doubt) (Cokley, 2000, 2002).

\section{General self-esteem, grade point average (GPA), and academic self-esteem}

It is essential to identify key factors and variables that are pivotal in understanding African Americans' academic self-esteem levels. Studies conducted examining ASE and variations of ASE highlight the existing relationship between (global) self-esteem and academic performance (Dollinger \& Clark, 2012; Steele-Johnson, \& Leas, 2013). In the existing literature, ASE levels have been shown to aid in predicting whether or not certain racial groups have higher or lower levels of academic performance. Studies tend to denote African American subjects as having lower academic performance levels (Brayfield et al., 1990; Dollinger \& Clark, 2012; Steele-Johnson \& Leas, 2013). A majority of studies that examine ASE focus primarily, or solely, on investigating the GSE and academic performance levels of White subjects.

\section{Academic performance and ASE}

Academic achievement has been established as a strong predictor of students' academic self-esteem, particularly in students with low academic achievement (Hope et al., 2013; Pullman \& Allik, 2008). Participants that utilized self-protective enhancement (motivation to maintain, elevate, and protect positive aspects of one's self-concept) and defensive pessimism (concept that high-performing and highly anxious individuals become accustomed to accomplishing success by increasing the fear of failure; Lim, 2009) displayed higher self-esteem or higher academic performance, respectively (Pullman \& Allik, 2008). Pullman and Allik's (2008) and Mackinnon and colleagues' (2015) studies displayed strong links between ASE levels, general self-esteem levels, GPA scores, academic assessment measures, and academic/self-esteem scales. In both studies, students who performed well on difficult tasks displayed higher levels of GSE and ASE There were positive correlations between high academic performance and high general self-esteem in the aforementioned studies (Pullman \& Allik, 2008; Mackinnon et al., 2015). While the studies provide evidence of links between GSE, ASE, and academic performance, they both utilize international samples. The cultural environments are not exactly transferable to African American/Black students learning higher educational contexts set in the U.S. The Pullman and Allik (2008) sample examined K-12 and collegiate level in Estonianspeaking institutions; the authors did not provide unique racial or ethnic characteristics. While Mackinnon et al. (2015) did not report participants' racial/ethnic demographics, the authors outlined that a bulk of the study's undergraduate samples were born in Canada (roughly 75\%), Asia (approximately ten percent), and Africa (roughly three percent).

\section{PERCEPTIONS OF TASK DIFFICULTY}

The amount of arousal or anxiety caused by completing a cognitive task is likely to influence both test performance and self-evaluations following task completion. When taking a test, heightened anxiety levels positively or negatively impact test performance (Teigen, 1994). The perceived difficulty of the task, when coupled with test-taker anxiety, can also have polarizing effects on test performance. The Yerkes-Dodson Law explains that test performance reaches an optimal level or peak as the individual assessed reaches a point of arousal that is neither too high nor too low (also referred to as the 
Optimal Arousal Theory; Yerkes \& Dodson, 1908). After an optimal level of arousal is reached, a reduction in performance is likely to occur if sensations of anxiety continue to increase (Broadhurst, 1957; Teigen, 1994). Participants are likely to experience different levels of anxiety based on task difficulty level (design) and personal perceptions of task difficulty. Subsequently, academic performance and ASE scores are expected to differ. African American students' perception of task rigor serves as an indicator of an external factor that has been shown to impact academic performance, self-esteem, and anxiety levels (Aruguete \& Hardy, 2016; Ross \& Broh, 2000; Stupnisky et al., 2007). Aruguete and Hardy (2016) opined that "Poor grades, combined with internal attributions and low expectations for success, may contribute to a negative emotional state among African American students" ( $\mathrm{p}$. 263).

Considering the Optimal Arousal Theory, it was anticipated that students in the low cognitive demand task (LCDT) condition would experience lower arousal and perhaps pay less attention to the task. Participants that perform poorly on a task considered to be "easy" are expected to demonstrate lower levels of self-esteem. Crocker and Wolfe (2001) found that individuals engaged in tasks of rigor reverted to self-protective self-evaluations to compensate for weakness in achievement. Further, researchers posit that difficult tasks increase the likelihood of students reverting to compensatory behaviors of inflating academic self-esteem (Crocker \& Wolfe, 2001). To this end, the congruent academic identification clusters (high self-esteem/high achievers and low self-esteem/low achievers) as well as the incongruent dis-identification clusters (high self-esteem/ low achievers and low selfesteem/high achievers) observed in Hope et al. (2013) provides rationalization for subsequent hypotheses of varying academic self-esteem levels by way of designed task rigor and students' academic performance.

\section{RESEARCH QUESTIONS AND HYPOTHESES}

The aims of this study were twofold: first, to determine if there were significant differences in mean barometric academic self-esteem (ASE) scores when considering academic performance (AP) and the designed task difficulty level (RQ1a); additionally, to assess for any noticeable gender differences in mean barometric ASE scores (RQ1b). Given trends surrounding arousal and perceptions of task difficulty (Hope et al., 2013), (H1) ASE levels were expected to differ between the two experimental groups (task difficulty levels) such that individuals completing the more difficult task would exhibit higher arousal levels, indicated by higher subject ratings of the task being challenging. Subsequently, these individuals would also display higher academic esteem than those completing the more manageable task. Since participants were provided accuracy feedback in the form of raw scores, then asked to calculate percentage scores, it was hypothesized that $(\mathrm{H} 2)$ academic performance would drive ASE levels with lower performing individuals having lower ASE than higher-performing participants. When considering the cognitive demand required of the task(s), based on the designed task rigor-level and possible performance levels (low or high performers, based on mean the split), it was hypothesized a trend $(\mathrm{H} 3)$ whereby ASE levels would differ with: LCDT low performers $\leq H C D T$ low performers $\leq L C D T$ high performers $\leq$ HCDT high performers. In examining possible gender differences between the African American students assessed, (H4) researchers expected women to have equal or higher levels of ASE when compared to men. The aforementioned trend was anticipated to persist in participants, regardless of gender (H5).

Analyses also examined if and to what extent barometric ASE levels varied based on GSE, GPA, subjects' perceptions of task difficulty, gender, and academic performance (AP) scores (RQ2). While it was expected general self-esteem and GPA to impact ASE in a significant and positive manner (H6), with higher scores in each yielding higher ASE scores, ASE scores were anticipated to vary indirectly with students' perceptions of task difficulty; students that perceive the tasks as more difficult were expected to have lower levels of ASE (H7). ASE levels were anticipated to vary significantly between men and women, such that women would have higher levels of esteem than men (H8). The primary aim of this study was to examine the extent to which academic performance (AP) influenced 
variance in ASE scores. When considering all variables assessed (H9), it was hypothesized that AP would account for a large portion of the variance in ASE scores. Moreover, students with higher performance levels were expected to have higher ASE scores.

\section{METHODOLOGY}

\section{PROCEDURES}

Before conducting the research, all components of the present study were approved by the University's Institutional Review Board. The researchers sent invitations to professors in the psychology, sociology, and criminal justice departments to assist in the solicitation of participants for the research. Participating instructors were provided a link that they then emailed to students and posted on their respective blackboard hubs, allowing potential participants to complete the study at their leisure. The web-link directed participants to the online study - developed using the Qualtrics assessment software. Data were collected within the first two months of the fall 2016 semester; students were allowed to complete assessment metrics in one sitting. Professors were encouraged to offer no more than $1 \%$ extra credit for completion. The researchers did not record if completion of the survey was a requirement, as a part of course extra credit, or voluntary.

\section{PARTICIPANTS}

All respondents were from a public HBCU in the southwestern region of the United States. Subjects for this study were gathered using a convenient sample. There were 468 student attempts of the online surveys assessments during the data collection window. After incomplete responses were removed, the final sample included 410 participants (107 self-identified as men, 303 as women). All participants self-identified racially as Black, with various composites of ethnicities. Participants' age ranged between 18 and $30(M=21 ; S D=2.33$ years). Students varied in collegiate classifications; 58 freshmen, 73 sophomores, 142 juniors, and 137 seniors completed the survey and assessment measures. The self-reported GPA of participants ranged from 0.5 to $4.0, M=2.89$ ( $S D=.61$ ).

\section{MEASURES}

This study utilized an online survey/assessment henceforth referred to as the Academic Performance and Academic Self-Esteem Survey. The survey included demographic questions, a general self-esteem measure, one of two equally and randomly assigned cognitive tasks, and an academic self-esteem measure. Tasks were administered in the aforementioned order.

\section{Demographic information}

Relevant to the present study, the demographic questionnaire allowed for the collection of selfreported information on participants' age, gender, racial and ethnic self-identification, classification, and cumulative grade point average. While the utilization of self-reported GPA may be considered a typical methodological limitation, this study uses student provided data as analyses in various educational contexts have found relatively high accuracy in respondent provided GPA and official grade point averages provided by institutions (see Caskie, Sutton, \& Eckhardt, 2014; Sticca et al., 2017).

\section{General self-esteem scale}

The general self-esteem scale measured participants' baseline self-esteem levels. The general selfesteem measure was developed using the Janis and Field's Feelings of Inadequacy assessment (1959). Participants responded to 30 questions $(a=0.83)$ using a five-point Likert-scale with selections of: Never to Always; or Strongly Disagree to Strongly Agree. Coding allowed for several items to be reverse coded such that a possible minimum score of 0 indicated low GSE and a maximum possible score of 120 indicated high GSE. The general self-esteem measure includes items such as: "How 
confident do you feel that someday the people you know will look up to you and respect you?" and "Have you ever felt ashamed of your physique or figure?"

\section{Cognitive demand task}

The Qualtrics online survey system allowed participants to be equally and randomly presented with one of the two 24 item cognitive tasks that were developed for the study: the Low Cognitive Demand Tasks (LCDT) and the High Cognitive Demand Task (HCDT). Questions on the low cognitive demand task were pooled from basic questions asked on $4^{\text {th }}, 5^{\text {th }}$, and $6^{\text {th }}$-grade examinations for U.S. students. Questions on the high cognitive demand task were pooled from $11^{\text {th }}$ and $12^{\text {th }}$-grade exams given to normally functioning U.S. students (Charles et al., 2014; Holt McDougal, 2012, 2014; McGraw-Hill Education, 2011; Spielvogel, 2012). Cronbach's alpha for low and high demand tasks were .77 and .54 (corrected a), respectively. Participants were presented with one - of four - subsection at a time. Participants answered academic questions in four areas of cognition: Reading \& Grammar, History \& Social Sciences, Mathematics \& Geometry, and Science. Each sub-section of the Cognitive Demand Task asked five questions to assess academic performance. Participants received one point per correct response and no points for incorrect responses. The possible academic performance (AP) scores range spans a range of 0 to 20 points. Note: After completing the cognitive demand task, students were shown raw score (i.e., 15/20) and then asked to calculate percentage scores; this allowed the typical format of feedback received for academic assignments (percentile score) to become more salient as student participants completed the Academic Self-Esteem Scale.

\section{Perception of difficulty}

After completing each sub-section of the CDT, an additional Likert-scale question, "How difficult did you find the preceding sections' questions to be?", gauged participant perception of task rigor; selection options range from Very Easy (1) to Very Difficult (5). This self-reported cognitive demand/level of difficulty score allows insight into perceived difficulty levels (PDL) and ranged from 4-20 points (4, representing perceptions of the task being "very easy;" 20 , representing perceptions of the task being "very difficult"; $\alpha=.85$ and $\alpha=.75$, with respect to PDL for low and high cognitive demand tasks).

\section{Academic self-esteem scale}

The Academic Self-Esteem Scale in the present study used items adapted from the Feelings of Inadequacy Scale and the Rosenberg Self-Esteem Scale (Janis \& Field, 1959; Rosenberg, 1965). The measure pooled items that assess academic and scholastic self-esteem (i.e., "How often do you have trouble understanding things you read for class assignments?"; and "Are your skills weaker than other people in your classes?"). The 20-item scale was coded in a way such that lower scores indicated lower academic self-esteem and higher scores indicated higher academic self-esteem $(a=.89)$. Scores for the academic self-esteem scale range from 0 to 80 , respectively denoting low to high scholastic selfesteem.

\section{STATISTICAL ANALYSES}

Pearson's correlations and several ANOVA tests were completed to compare the means of participant's academic self-esteem based on task difficulty levels, performance levels (high or low performers given mean split calculations), and gender. In addressing the second research question, a multiple regression analysis was conducted to evaluate the extent to which academic performance, and other independent variables, impacted the variance in ASE scores. 


\section{RESULTS}

\section{DESCRIPTIVE STATISTICS}

General self-esteem scores ranged from 31 to $106(M=72.59, S D=13.57)$ indicating that on average, participant levels of GSE fell slightly above the median score; descriptive statistics provided in Table 1 . There was an average academic performance of $77 \%$ with a standard deviation of $17 \%$. Upon further review, the 203 participants randomly presented with the lower demand task demonstrated an average performance accuracy of $89.36 \%(M=17.87, S D=2.36)$; LCDT scores were non-normal distributed, with a skewness of $-1.84(S E=.17)$ and kurtosis of $3.66(S E=.34$; a significant portion of these participants performed at the top $25^{\text {th }}$ percentile). The 207 participants administered the HCDT demonstrated an average performance accuracy of $65.9 \%(M=13.18, S D=2.69)$; HCDT scores were normally distributed. Perceived difficulty levels (PDL) for the LCDT indicate that respondents felt the task was "easy" $(M=7.86, S D=3.12)$; PDL for those that completed the HCDT indicate that, on average, these participants felt the task was "neither easy nor difficult," $(M=12.25$, $S D=2.94)$. Academic self-esteem scores ranged from 18 to $79(M=52.26, S D=11.38)$ and were normally distributed; on average, men held higher ASE scores $(M=54.21, S D=12.72)$ than women $(M=51.58, S D=10.80)$.

Table 1. Descriptive Statistics

\begin{tabular}{lllllllll}
\hline & \multirow{2}{*}{$M$} & \multirow{2}{*}{$S D$} & Min. & Max. & \multicolumn{2}{c}{ Skewness } & \multicolumn{2}{c}{ Kurtosis } \\
& & & & & & SE & & SE \\
\hline Academic Self-Esteem & 52.26 & 11.38 & 18 & 79 & 0.05 & 0.12 & -0.47 & 0.24 \\
General Self-Esteem & 72.59 & 13.58 & 31 & 106 & -0.26 & 0.12 & -0.20 & 0.24 \\
Grade Point Average & 2.90 & 0.61 & 0.5 & 4 & -0.96 & 0.12 & 3.05 & 0.24 \\
Academic Performance $(\%)$ & 0.78 & 0.17 & 0.25 & 1 & -0.44 & 0.12 & -0.89 & 0.24 \\
Cognitive Demand Task & 0.50 & 0.50 & 0 & 1 & -0.02 & 0.12 & -2.01 & 0.24 \\
Perception of Difficulty & 10.08 & 3.74 & 4 & 20 & 0.20 & 0.12 & -0.48 & 0.24 \\
Gender of Participant & 0.26 & 0.44 & 0 & 1 & 1.09 & 0.12 & -0.81 & 0.24 \\
\hline
\end{tabular}

Note: $n=410$.

\section{BIVARIATE CORRELATIONAL ANALYSES}

Pearson's correlations were computed for variables of interest, provided in Table 2 . The main variable of interest, academic self-esteem (ASE), was found to be significantly related to all other variables. Significant relationships between GSE and ASE $(r=.66, p<.001)$ indicate a strong positive correlation. Grade point average and academic self-esteem scores show a negligible, positive correlation $(r=.10, p=.04)$. As performance scores on developed cognitive demand tasks increased, so did levels of academic self-esteem $(r=.30, p<.001)$. Cognitive demand task level, low versus high (dummy coded 0 and 1 , respectively), was found to associate negatively with academic self-esteem; higher demand conditioned participants typically yielded lower ASE scores $(r=-.15, p=.003)$. There were inverse relationships between subjects' perceptions of task difficulty and ASE. Overall $(r=-.29$, $p<.001)$, the ASE scores were typically lower for participants that found the academic task more challenging; the same is true regarding perceptions surrounding low and high cognitive demand tasks $(r=-.29, p<.001 ; r=-.21, p<.001$, respectively). The marginally significant positive correlation for gender and academic self-esteem denotes relatively higher ASE levels in men (1) in comparison to women (0). 
Table 2. Pearson's Zero Ordered Correlations for Variables of Interest

\begin{tabular}{|c|c|c|c|c|c|c|}
\hline 1 & 2 & 3 & 4 & 5 & 6 & 7 \\
\hline 1. Academic Self-Esteem & $0.66^{* *}$ & $0.10^{*}$ & $.30^{* *}$ & $-0.15^{* *}$ & $-0.29 * *$ & $0.10^{*}$ \\
\hline 2. General Self-Esteem & & 0.02 & $0.19 *$ & -0.07 & $-0.12^{*}$ & $0.10^{*}$ \\
\hline 3. Grade Point Average & & & 0.01 & 0.06 & -0.05 & -0.05 \\
\hline 4. Academic Performance (\%) & & & & $-0.68^{* *}$ & $-0.60 * *$ & 0.06 \\
\hline 5. Cognitive Demand Task Level & & & & & $0.59 * *$ & $-0.12^{*}$ \\
\hline 6. Perception of Difficulty & & & & & & $-0.15^{* *}$ \\
\hline 7. Gender & & & & & & \\
\hline
\end{tabular}

Note: $n=410$. Cognitive Demand Task Level coded as $0=$ low cognitive demand task and $1=$ high cognitive demand task. Gender coded for $0=$ women and $1=$ men. $*=p<.05,{ }^{*}=p<.01$

\section{FACTORIAL ANOVA MEAN COMPARISONS BY ASE}

\section{Between academic performance and task difficulty}

Barometric academic self-esteem (ASE) scores differed when considering the designed difficulty levels of the cognitive tasks and students' academic performance (AP) levels, as presented in Table 3. Students that completed the Low Cognitive Demand Task had significantly higher levels of ASE than students that completed the HCDT (mean difference of 3.34, $p=.003$ ) (H1); thus, rejecting the first hypothesis. As hypothesized, low performers had significantly lower ASE levels than high performers, regardless of designed task difficulty level (mean difference of 4.68, $p<.01)(\mathrm{H} 2)$.

To examine differences in ASE when considering both task difficulty and students' actual performance, ANOVA comparison models revealed several findings. On average, the students that completed that the Low Cognitive Demand Task and performed well (above the mean) displayed higher levels of academic self-esteem than students performing below par on the High Cognitive Demand Task (mean difference of $6.70, d=.63, p<.001$ ). Another comparison revealed significantly lower levels of mean ASE in High Cognitive Demand low performing students $(M=48.23)$ than High Cognitive Demand Task high performing students $(M=53.31$; mean difference of $5.08, d=.47, p<$ .001). When considering the designed difficulty level of the task and students' actual performance on the developed academic task, results indicate a trend where the academic self-esteem levels in the given sample differ accordingly: High Cognitive Demand Task low performers $\leq$ Low Cognitive Demand Task low performers $\leq$ High Cognitive Demand Task high performers $\leq$ Low Cognitive Demand Task high performers.

These results partially confirm the third hypothesis. It was hypothesized that the comparisons between task difficulty level and performance combinations would drive any observed difference in mean academic self-esteem, such that Low Cognitive Demand Task low performers $\leq$ High Cognitive Demand Task. low performers $\leq$ Low Cognitive Demand Task high performers $\leq$ High Cognitive Demand Task high performers. Results confirmed that lower levels of ASE were observed in lower performing students. It was anticipated that performing well on a more difficult task would lead to higher levels of selfesteem; however, results indicate ASE to be lower in students that completed the more difficult task.

\section{Between gender}

Comparisons of mean ASE scores based on task demand level, performance level, and gender, revealed significantly lower levels of academic self-esteem in women, of the given sample: mean difference of 2.63, $d=.22, p<.05$ (see Table 3). African American women were projected to have equal or higher levels of GSE when compared to African American men; based on results obtained, the null hypothesis is rejected (H4). 
Further analysis revealed that trends for men and women mirrored that of the overall sample (confirming the hypothesis H5). For men in the sample: High Cognitive Demand Task low performer ASE scores, $M=48.58(S D=10.87)<$ Low Cognitive Demand Task low performer ASE scores, $M$ $=53.00(S D=12.84)<$ High Cognitive Demand Task high performer ASE scores, $M=56.37(S D=$ $16.48)<$ Low Cognitive Demand Task high performer ASE scores, $M=56.72(S D=11.32)$.

Table 3. Comparisons of Mean Academic Self-Esteem Scores

\begin{tabular}{|c|c|c|c|c|c|c|}
\hline $\begin{array}{l}\text { Task Demand and Per- } \\
\text { formance Level }\end{array}$ & ASE & $S D$ & Mean Diff. & Effect Size & Cohen's $d$ & $n$ \\
\hline $\begin{array}{l}\text { Low Cognitive Demand } \\
\text { Task (LCDT) }\end{array}$ & 53.95 & 11.39 & & & & 203 \\
\hline $\begin{array}{l}\text { High Cognitive De- } \\
\text { mand Task (HCDT) }\end{array}$ & 50.61 & 11.14 & -3.34 & 0.147 & 0.296 & 207 \\
\hline Low Performers & 49.58 & 10.63 & & & & 175 \\
\hline High Performers & 54.26 & 11.52 & -4.68 & -0.206 & -0.422 & 235 \\
\hline LCDT Low Performer & 51.88 & 11.35 & & & & 65 \\
\hline LCDT High Performer & 54.93 & 11.32 & -3.05 & -0.133 & -0.269 & 138 \\
\hline HCDT Low Performer & 48.23 & 9.99 & 3.65 & 0.168 & 0.341 & 110 \\
\hline HCDT High Performer & 53.31 & 11.79 & -1.43 & -0.062 & -0.123 & 97 \\
\hline LCDT High Performer & 54.93 & 11.32 & & & & 138 \\
\hline LCDT Low Performer & 51.88 & 11.35 & 3.05 & 0.133 & 0.269 & 65 \\
\hline HCDT Low Performer & 48.23 & 9.99 & 6.7 & 0.299 & 0.628 & 110 \\
\hline HCDT High Performer & 53.31 & 11.79 & 1.62 & 0.069 & 0.14 & 97 \\
\hline HCDT Low Performer & 48.23 & 9.99 & & & & 110 \\
\hline LCDT Low Performer & 51.88 & 11.35 & -3.65 & -0.168 & -0.341 & 65 \\
\hline LCDT High Performer & 54.93 & 11.32 & -6.7 & -0.299 & 0.628 & 138 \\
\hline HCDT High Performer & 53.31 & 11.79 & -5.08 & -0.226 & -0.465 & 97 \\
\hline HCDT High Performer & 53.31 & 11.79 & & & & 97 \\
\hline LCDT Low Performer & 51.88 & 11.35 & 1.43 & 0.062 & 0.123 & 65 \\
\hline LCDT High Performer & 54.93 & 11.32 & -1.62 & -0.133 & -0.269 & 138 \\
\hline HCDT Low Performer & 48.23 & 9.99 & 5.08 & 0.226 & 0.465 & 65 \\
\hline Men & 54.21 & 12.72 & & & & 107 \\
\hline Women & 51.58 & 10.8 & 2.63 & 0.111 & 0.222 & 303 \\
\hline
\end{tabular}

In women, the trend persisted: High Cognitive Demand Task low performer ASE scores, $M=48.13$ $(S D=9.79)<$ Low Cognitive Demand Task low performer ASE scores, $M=51.45(S D=10.84)<$ High Cognitive Demand Task high performer ASE scores, $M=52.56(S D=10.34)<$ Low Cognitive Demand Task high performer ASE scores, $M=54.03(S D=11.37)$ Future research may allow for further, more in-depth, analysis of gender differences. 


\section{ASE AS PREDICTED BY FACTORS ASSESSED}

The second major objective of the study was to determine if academic self-esteem (ASE) levels varied subsequent to participants' academic performance (AP). A listwise regression analysis; $\hat{Y}=$ $B_{1}$ Academic Performance $_{1}+B_{2}$ General self-esteem $2+B_{3}$ Perceived difficulty $_{3}+B_{4} G P A_{4}+B_{5} G e n d e r_{5}+B_{0}$; allowed us to determine if academic self-esteem varied based on proceeding academic performance or other assessed independent variables (see Table 4). The linear combination of predictors proved significant $R^{2}=.497, F(5,404)=79.71, p<.01$, with exception to gender $(p=.76)$. When considering other factors, ASE levels did not vary significantly by gender; thus, rejecting the hypothesis related to gender as an anticipated predictor (H8). A second multiple stepwise regression without gender as a predictor variable was analyzed (see Table 4$) ; \hat{Y}=B_{1}$ Academic Performance $_{1}+B_{2}$ General self-

esteem $_{2}+B_{3}$ Perceived difficulty $3+B_{4} G P A_{4}+B_{0}$. The linear combination of predictors for this model proved significant to variances in ASE, $R^{2}=.496, F(4,405)=99.83, p<.01$. Beta coefficients revealed a positive relationship whereby higher GSE $(\beta=0.53, p<.01)$ and higher self-reported grade point averages $(\beta=1.41, \mathrm{p}<.05)$ were indicative of higher academic self-esteem levels; findings confirm our hypothesis H6. Negative beta coefficients for perceived difficulty levels $(\beta=-.48, p<.01)$ confirm the hypothesis H7; when controlling for other assessed factors, ASE levels varied in a negative fashion as participants' perceptions of task difficulty increased. Academic self-esteem varied significantly and positively based on subjects' academic performance $(\beta=6.03, p<.05)$; based on the results the null hypothesis is accepted (H9).

Table 4. Regression Models for Academic Self-Esteem as Predicted by Variables of Interest

\begin{tabular}{|c|c|c|c|c|c|}
\hline Variable & $B$ & Std. Error & Beta & $t$ & p-value \\
\hline \multicolumn{6}{|l|}{ (Model I- listwise results) } \\
\hline Constant & 10.07 & 4.27 & & 2.36 & 0.019 \\
\hline General Self-esteem & 0.52 & 0.03 & 0.62 & 17.32 & 0.000 \\
\hline Academic Performance & 6.08 & 2.94 & 0.09 & 2.07 & 0.039 \\
\hline Perception of Difficulty & -0.47 & 0.13 & -0.15 & -3.48 & 0.001 \\
\hline Grade Point Average & 1.43 & 0.66 & 0.08 & 2.17 & 0.031 \\
\hline Gender & 0.29 & 0.93 & 0.01 & 0.312 & 0.756 \\
\hline \multicolumn{6}{|c|}{ (Model II - stepwise results) } \\
\hline Constant & 10.21 & 4.24 & & 2.41 & 0.016 \\
\hline GSE & 0.53 & 0.3 & 0.63 & 17.45 & 0.000 \\
\hline Academic Performance & 6.03 & 2.93 & 0.09 & 2.06 & 0.040 \\
\hline Perception of Difficulty & -0.48 & 0.13 & -0.16 & -3.57 & 0.000 \\
\hline Grade Point Average & 1.41 & 0.66 & 0.08 & 2.16 & 0.032 \\
\hline
\end{tabular}

Using this second regression, R-squared and R-squared change values allowed us to examine the amount of variability accounted for by adding each independent variable. While the full model accounts for roughly half of the variability seen in ASE scores among participants, baseline general self-esteem values accounted for a majority (44\%) of the variance explained. R-squared change values denote subjects' perceptions of task difficulty as being the next influential variable $\left(\Delta \mathrm{R}^{2}=.045 ; p<\right.$ $.01)$; PDL accounted for an additional $4.5 \%$ of variability in ASE in the given sample. Adding selfreported GPA $\left(\Delta R^{2}=.006 ; p<.05\right)$ and academic performance $\left(\mathrm{AP} ; \Delta \mathrm{R}^{2}=.005 ; p<.05\right)$ marginally impacted changes in ASE scores. 


\section{DISCUSSION}

The primary focus of this study was to examine if students' academic self-esteem levels varied based on their performance on an academic task (e.g., easy vs. difficult cognitive task) and to determine if traditional trends of gender differences in esteem proved evident in a sample of Back/HBCU students. Results indicate that academic self-esteem (ASE) scores differ based on both the design, task cognitive demand level and students' academic performance. Results also indicate the importance of students' feelings towards task difficulty, actual performance on an assessment, and subsequent selfesteem. All participants were informed of their academic performance scores prior to completing the academic self-esteem measure. Students that performed below the mean on a difficult task had lower ASE levels than students that performed below the mean on a task with perceived ease; this goes against initial expectations. The same trend persisted in scores of those that performed above the mean. Students were expected to feel better about themselves when performing well on a more difficult task. These results imply that task difficulty under shadow confidence and subsequent selfesteem levels, even when performing well. It is important to note that the multiple comparisons which examined academic self-esteem levels based on task difficulty and academic performance revealed a consistent and significant difference between the High Cognitive Demand Task low performers (lowest ASE) and the Low Cognitive Demand Task high performers (highest ASE) only. The likelihood of students' academic self-esteem scores falling within the median of a given sample (at $2^{\text {nd }}$ or $3^{\text {rd }}$ place, if you will) varies between the other two conditions $($ LCDT low performers $\leq$ or $\geq$ HCDT high performers).

Taking into consideration the Optimal Arousal Theory, it was posited that the easier a task was perceived to be (linked to performance anxiety) the more likely individuals were to perform well on said task. From the results, academic performance influenced participants' current psycho-emotional state, or barometric academic self-esteem, as reflected by the varying levels of ASE scores. Students that completed more difficult tasks had lower self-perceptions about their cognitive abilities, but performance on either task administered also proved to impact students' views of self. Furthermore, the findings indicate that students' perception of task rigor holds more weight than academic performance.

The implications of these findings are imperative in that they allow for an understanding of selfesteem within students, as well as inform us of various components of self-esteem maintenance within African American college students. Universities can use these findings to aid in the development of curriculum and educational tools used to help increase the self-esteem and academic selfesteem. Taking into consideration the links between academic performance and educational attainment and the dismal graduation rates of students, particularly African American students, educators must use every measure possible to ensure students successfully matriculating through their respective programs (Cheng et al., 2015; Gershenfeld et al., 2015; NCES, 2017); In the given student sample, African American men had significantly higher ASE levels than women. This finding is particularly fascinating given the statistics that suggest African American women have higher graduation rates than African American men and HBCU graduation rates as being positively influenced by the institutions' percentage of female students (Cheng et al., 2015; NCES, 2017). Future research may seek to examine the extent to which African Americans attend college for economic gains and consider the factors that contribute to female students of color earning degrees at a higher rate than African American male college students (US Census Bureau, 2017). This particular study reveals that African American women who attend an HBCU think slightly less of their academic abilities, even though they do not perform differently from their male counterpart.

The second aim of the study was to determine if academic self-esteem varied based on academic performance, general self-esteem, perceived difficulty, GPA, and gender of participants within the given sample. All variables, except gender, had a significant impact on ASE levels. Above and beyond those analyzed in the present study, academic self-esteem is likely to be influenced by a multitude of 
factors. Considering the findings, while academic performance did significantly impact HBCU students' self-reported levels of academic self-esteem, students' perceptions of task rigor had more of an impact on subsequent self-evaluations. Given the line of research that has already established a link between academic self-esteem and academic performance (Gebauer et al., 2015; Josephs et al., 1992; Kling et al., 1999; von Soest et al., 2016), a possible implication of the present study findings would entail instructional development, curriculum improvement, and assessment reform. Improving professors' ability to gauge and address students' perceptions of task rigor can inevitably lead to increased students' academic success and psycho-emotional stability following assessments. It is important that HBCU administrators and educators remain mindful of students' mental stability and possible ramifications on capabilities (performance). From examining students attending an HBCU, a deeper understanding of academic self-esteem and its role in academia can be obtained. This clarity may help universities meet a principal objective - the ability to produce the next wave of efficacious African American scholars.

Several limitations to the present study must be noted. The current study analyzed Black students (African American and individuals of Afro-descent) that attended one HBCU located in the southeastern region of the U.S.; the demographics of the sample may influence the generalizability of the results. It is possible that African American/Black students attending other HBCUs, or Minority Serving Institutions (MSI), may experience different learning or contextual factors which could impact the variables of interest. The present study did not examine students' perceptions of societal norms, worldviews, or perceptions of task saliency. Students' drive, motives, and attitudes were not assessed but may have influenced self-reported academic-based esteem concepts. The low internal reliability of the high demand task is a possible methodological limitation of the present study. Additionally, the study sample relied on students that completed various courses within specified social science disciplines. While some of the courses were foundational, general education requirement courses (i.e., Human Growth and Development), it is possible that results may have varied in a broader sample. Given these limitations, findings and suggested implications should be construed with care.

While the present study helps educators to establish an understanding that ASE differs based on academic performance and task difficulty, there still exist other questions that need answers. Future research should examine other factors that influence academic self-esteem - in addition to GSE and perceived difficulty. Students' ASE may vary pending intrinsic or extrinsic motivation levels. Research has suggested that African American students' academic success is positively correlated with extrinsic factors (i.e., potential starting salary, social/economic mobility) (Cheng et al., 2015). The current study is flawed in the predictive capability of ASE as general self-esteem was assessed to gain a baseline of overall self-esteem. It is possible that students' gained insight into the study's intent and answered subsequent ASE questions with social perceptions in mind. Future research studies may randomly present students with an ASE evaluation task or an academic task (alternating task order) then evaluate differences in correlations based on task presentation. Given the limit of low internal reliability for one of the academic tasks, future studies may utilize curriculum-based measures to assess cognition. It is likely that students will exert more effort and experience higher anxiety when academic tasks count for a course grade. With this in mind, instructors may want to gauge task difficulty and assess academic self-esteem after an actual course assignment or test. While the present study findings did not indicate gender as a predictor of academic self-esteem, future research should focus on the degrees to which individuals' perceptions of (academic) self-concepts differ by gender and as they attend and matriculate through various educational contexts.

In addition to the components examine here, previous studies have highlighted other elements that relate to and are influential toward African American college students' perceptions of their scholastic capabilities. Most recently, Brown, Rosnick, and Segrist (2017) found inverse correlations between African American $(n=156)$ students' locus of control (one's level of control over one's academic/life outcomes) and the extent to which they valued higher education $(r=-0.66, p<.001)$. Addi- 
tionally, this belief of academic control (e.g., personal control and self-esteem) was shown to mediate the extent to which internalized racial oppression impacted male students' value of higher education (Brown et al., 2017; Ross \& Broh, 2000). In the finding presented by Lige, Peteet, and Brown (2017), African American students' $(n=112)$ general self-esteem levels were found to be directly correlated with and impacted by their private regard/racial identify (assessed by participants' feelings toward African Americans and their membership in the group; p. 349); $r=.46, p<.01 ; \beta=.23, p<.001$, respectively. Additionally, these elements of self-esteem mediated the extent to which students displayed negative self-beliefs characterized by a persistent perception of incompetence despite contrary evident (the impostor phenomenon; Clance \& Imes, 1978 - as cited by Lige et al., 2017). Given these findings, future researchers may wish to examine additional factors that relate to and influence students' self-esteem, self-efficacies, and feelings of control; particularly those relative to academic success.

\section{CONCLUSION}

While major aims were to examine if and to what extent HBCU students' academic self-esteem levels differ and vary when considering academic performance (via performance feedback) and baseline self-esteem, a major finding was the importance of students' perceptions of task difficulty on subsequent academic self-esteem levels. Additionally, this study helps to establish a line of research on Black students at a relatively racially homogenous educational institution. Given the literature which suggests strong links between school racial composites and students' success (Cokley, 2000, 2002), it is likely that these students' feelings of ability vary directly with previously established general selfconcepts, performance, and perceptions of task difficulties, and previous academic and other factors (e.g., faculty support, sense of campus cohesion, etc.) (DeFreitas, 2012). Most notably, while there were no gender differences in performance, men displayed higher levels of ASE when compared to women. Given the overlap between elements of general self-esteem and academic self-esteem, the possible effects of multicollinearity between initial and academic self-efficacies influenced study findings. Finally, this study presents a need for newer research to examine students' perceptions of task rigor as a potential factor in self-esteem and academic success. Far too often, the literature has sought to determine how esteem and self-concepts impact academic performance; however, experiences of success and failures may inevitably impact aspects such as students' intrinsic motivation, levels of self-efficacies, as well as risk of learned helplessness (Brown et al., 2017; Lige et al., 2017). Only through a holistic analysis can researchers, policymakers, and educators help to bring about change higher student academic-self-esteem and academic achievement.

\section{REFERENCES}

Aruguete, M. S., \& Hardy, P. M. (2016). Performance attributions of African American and White college students. North American Journal of Psychology, 18(2), 257-268. Retrieved from

https://login.proxy.lib.fsu.edu/login?url=https:// search-proquestcom.proxy.lib.fsu.edu/docview/1856863911?accountid $=4840$

Baker, C. N. (2015). Gender differences in the experiences of African American college students: The effects of co-ethnic support and campus diversity. Women, Gender, and Families of Color, 3(1), 36-57. University of Illinois Press. Retrieved on September 24, 2018 from https://muse.jhu.edu/article/579808

Brayfield, A. A., Adler, M. A., \& Zablotsky, D. L. (1990). Gender, race, and cultural literacy: Consequences for academic performance. Teaching Sociology, 18(3), 362-371. https://doi.org/10.2307/1317739

Broadhurst, P. L. (1957). Emotionality and the Yerkes-Dodson Law. Journal of Experimental Psychology, 54(5), 345352. https://doi.org/10.1037/h0049114

Brown, D. L., Rosnick, C. B., \& Segrist, D. (2017). Internalized racial oppression and higher education values: The mediational role of academic locus of control among college African American men and women. Journal of Black Psychology, 43(3), 358-380. https://doi.org/10.1177/0095798416641865 
Buddington, S. A., \& Haydel, N. (2015). Historically Black and colleges and universities first-year students/ freshpersons-urban students: Gender, academic achievement, basic emotional wellness and educational outlook. Journal of Education and Social Justice, 3(1), 12-20. Retrieved from https://login.proxy.lib.fsu.edu/login?url=http://search.ebscohost.com/login.aspx?direct $=$ true $\& d b=e u e \&$ $\underline{\mathrm{AN}}=123117339 \&$ site $=$ eds-live

Caskie, G., Sutton, M. C., \& Eckhardt, A. G. (2014). Accuracy of self-reported college GPA: Gendermoderated differences by achievement level and academic self-efficacy. Journal of College Student Development, 55(4), 385-390. https://doi.org/10.1353/csd.2014.0038

Chapell, M. S. \& Overton, W. F. (2002). Development of logical reasoning and the school performance of African American adolescents in relation to socioeconomic status, ethnic identity, and self-esteem. Journal of Black Psychology, 28(4), 295-317. https://doi.org/10.1177/009579802237539

Charles, R., Hall, B., Kennedy, D., Bass, L., Johnson, A., Murphy, S., \& Wiggins, G. (2014). Geometry: Teacher's Edition 2-Volume Set (Common Core). Pearson.

Cheng, X., Suwanakul, S., \& Wu, R. (2015). Determinants of graduation rates of Historically Black Colleges and Universities. Journal of Economics and Economic Education Research, 16(2), 51-60.

Clance, P. R., \& Imes, S. A. (1978). The impostor phenomenon in high-achieving women: Dynamics and therapeutic intervention. Psychotherapy: Theory, Research \& Practice, 15, 241-247. https://doi.org/10.1037/h0086006

Cokley, K. (2000). An investigation of academic self-concept and its relationship to academic achievement in African American college students. Journal of Black Psychology, 26(2), 148-164. https://doi.org/10.1177/0095798400026002002

Cokley, K. (2002). Ethnicity, gender, and academic self-concept: A preliminary examination and academic disidentification and implications for psychologists. Cultural Diversity \& Ethnic Minority Psychology,8(4), 378-388. https://doi.org/10.1037/1099-9809.8.4.379

Crocker, J., \& Wolfe, C. T. (2001). Contingencies of self-worth. Psychological Review, 108, 593-623. https://doi.org/10.1037/0033-295X.108.3.593

Davis-Kean, P. E. \& Sandler, H. M. (2001). A meta-analysis of measures of self-esteem for young children: A framework for future measures. Child Development, 72(3) 887-906. https://doi.org/10.1111/1467$\underline{8624.00322}$

DeFreitas, S. C. (2012). Difference between African American and European American first-year college students in the relationship between self-efficacy, outcome expectations, and academic achievement. Social Psychology Education, 15(1), 109-123. https://doi.org/10.1007/s11218-011-9172-0

Dollinger, S. J., \& Clark, M. H. (2012). Test-taking strategy as a mediator between race and academic performance. Learning and Individual Differences, 22(4), 511-517. https://doi.org/10.1016/j.lindif.2012.03.010

Fries-Britt, S. L., \& Turner, B. (2001). Facing stereotypes: A case study of black students on a white campus. Journal of College Student Development. 42(5), 420-429.

Gebauer, J. E., Sedikides, C., Wagner, J., Bleidorn, W., Rentfrow, Peter J., Potter, J., \& Gosling, S. D. (2015). Cultural norm fulfillment, interpersonal belonging, or getting ahead? A large-scale cross-cultural test of three perspectives on the function of self-esteem. Journal of Personality and Social Psychology, 109(3), 526-548. https://doi.org/10.1037/pspp0000052

Gershenfeld, S., Hood, D. W., \& Zhan, M. (2015). The role of first-semester GPA in predicting graduation rates of underrepresented students. Journal of College Student Retention, 17(4), 469-488. https://doi.org/10.1177/1521025115579251

Gray-Little, B. \& Hafdahl, A. R. (2000). Factors influencing racial comparisons of self-esteem: A quantitative review. American Psychological Association, 126(1), 26-54. https://doi.org/10.1037//0033-2909.126.1.26

Harter, S. \& Whitesell, N. (2003). Beyond the debate: Why some adolescents report stable self-worth over time and situation, whereas others report changes in self-worth. Journal of Personality, 71(6), 1027-1058.

https://doi.org/10.1111/1467-6494.7106006 
Hoffman, A. J., Knight, L. F. M., \& Wallach, J. (2007). Gardening activities, education, and self-esteem: Learning outside the classroom. Urban Education, 42(5), 403-411. https://doi.org/10.1177/0042085907304909

Holt McDougal. (2012). Holt McDougal world history: Patterns of Interaction (1st ed.). Author. ISBN: 9780547601373.

Holt McDougal. (2014). Houghton Mifflin Harcourt collections Florida: Student edition (1st ed.). Author. ISBN: 9780544092242 .

Hope, E. C., Chavous, T. M., Jagers, R. J., \& Sellers, R. M. (2013). Connecting self-esteem and achievement: Diversity in academic identification and dis-identification patters among Black college students. American Educational Research Journal, 50(5), 1122-1151. https://doi.org/10.3102/0002831213500333

Janis, I. L., \& Field, P. B. (1959). Sex differences and factors related to persuasibility. In C. I. Hovland \& I. L. Janis (Eds.), Personality and persuasibility (pp. 55-68). New Haven, CT: Yale University Press. ISBN: 03000060049780300006001

Josephs, R. A., Tafarodi, R. W. \& Markus, H. R. (1992). Gender and self-esteem. Journal of Personality and Social Psychology, 63(3), 391-402. https://doi.org/10.1037/0022-3514.63.3.391

Kernis, M., Grannemann, B., \& Barclay, L. (1989). Stability and level of self-esteem as predictors of anger arousal and hostility. Journal of Personality and Social Psychology, 56(6), 1013-1022. https://doi.org/10.1037/0022-3514.56.6.1013

Kling, K. C., Hyde, J. S., Showers, C. J., \& Buswell, B. N. (1999). Gender differences in self-esteem: A metaanalysis. Psychological Bulletin, 125(4), 470-500. https://doi.org/10.1037/0033-2909.125.4.470

Lige, Q. M., Peteet, B. J., \& Brown, C. M. (2017). Racial identity, self-esteem, and the imposter phenomenon among African American college student. Journal of Black Psychology, 43(4), 345-357. https://doi.org/10.1177/0095798416648787

Lim, L., (2009). A two-factor model of defensive pessimism and its relations with achievement motives. The Journal of Psychology, 143(3), 318-336. https://doi.org/10.3200/JRLP.143.3.318-336

Lipnevich, A. A. (2006). Low self-esteem: Myth or reality? Focus on Basics, 8(B), 1-5. http://ncsall.net/fileadmin/resources/fob/2006/fob 8b.pdf

Lockett, C. T. \& Harrell, J. P. (2003). Racial identity, self-esteem, and academic achievement: Too much interpreting, too little supporting data. Journal of Black Psychology, 29(3), 325-336. https://doi.org/10.1177/0095798403254216

Mackinnon, S. P., Smith, S. M. \& Carter-Rogers, K. (2015). Multidimensional self-esteem and test derogation after negative feedback. Canadian Journal of Behavioral Science, 47(1), 123-126. https://doi.org/10.1037/a0038364

McGraw-Hill Education. (2011). Glencoe Biology, Student Edition (Biology Dynamics of Life) (1st ed.). Author. ISBN: 978-0076774289

National Center for Education Statistics (NCES). (2017). U.S. Department of Education, Integrated Postsecondary Education Data System (IPEDS), Spring 2002 through Spring 2013 and Winter 2013-14 through Winter 2015-16, Graduation Rates component; and IPEDS Fall 2009, Institutional Characteristics component. (This table was prepared October 2016.) https://nces.ed.gov/programs/digest/d16/tables/dt16 326.10.asp

Oates, G. L. (2004). The color of the undergraduate experience and the Black self-concept: Evidence from longitudinal data. Social Psychology Quarterly, 67(1) 16-32. https://doi.org/10.1177/019027250406700104

Okech, A., \& Chambers, C. R. (2012), Gender differences in self-actualization. In C. R. Chambers \& R. Vonshay Sharpe (Eds.), Black female undergraduates on campus: Successes and challenges (Diversity in higher education, Volume 12) (pp.59-74). Emerald Group Publishing Limited.

Pullman, H., \& Allik, J. (2008). Relations of academic and general self-esteem to school achievement. Personality and Individual Differences, 45(6), 559-564. https://doi.org/10.1016/i.paid.2008.06.017

Rosenberg, M. (1965). Society and the adolescent self-image. Princeton, NJ: Princeton University Press. https://doi.org/10.1515/9781400876136 
Ross, C. E. \& Broh, B. A. (2000). The roles of self-esteem and the sense of personal control in the academic achievement process. Sociology of Education, 73(4), 270-284. https://doi.org/10.2307/2673234

Spielvogel, J. (2012). Western civilization (8th ed.). Belmont, Calif.: Wadsworth Cengage Learning. ISBN-13: 9781285436401, ISBN-10: 1285436407

Sprecher, S., Brooks, J. E., \& Avogo, W. (2013). Self-esteem among young adults: Differences and similarities based on gender, race, and cohort (1990-2012). Sex Roles, 69(5-6), 264-275. https://doi.org/10.1007/s11199-013-0295-y

Steele, C. M., \& Aronson, J. (1995). Stereotype threat and the intellectual test performance of African Americans. Journal of Personality and Social Psychology, 69, 797-811. https://doi.org/10.1037/0022-3514.69.5.797

Steele-Johnson, D., \& Leas, K. (2013). Importance of race, gender, and personality in predicting academic performance. Journal of Applied Social Psychology, 43(8), 1736-1744. https://doi.org/10.1111/jasp.12129

Sticca, F., Goetz, T., Bieg, M., Hall, N. C., Eberle, F., \& Haag, L. (2017). Examining the accuracy of students' self-reported academic grades from a correlational and a discrepancy perspective: Evidence from a longitudinal study. PLOS ONE, 12(11): e0187367. https://doi.org/10.1371/journal.pone.0187367

Stupnisky, R. H., Renaud, R. D., Perry, R. P., Ruthig, J. C., Haynes, T. L., \& Clifton, R. A. (2007). Comparing self-esteem and perceived control as predictors of first-year college students' academic achievement. Social Psychology of Education, 10(3), 303-330. https://doi.org/10.1007/s11218-007-9020-4

Teigen, K. H. (1994). Yerkes-Dodson: A law for all seasons. Theory \& Psychology, 4(4) 525-547. https://doi.org/10.1177/0959354394044004

Tempel, T. \& Neumann, R. (2014) Stereotype threat, test anxiety, and mathematics performance. Social Psychology of Education, 17(3), 491-501. https://doi.org/10.1007/s11218-014-9263-9

Thames, A., Hinkin, C., Byrd, D., Bilder, R., Duff, K., Mindt, M., Arentoft, A., \& Streiff, V. (2013). Effects of stereotype threat, perceived discrimination, and examiner race on neuropsychological performance: Simple as Black and White? Journal of the International Neuropsychological Society, 19(5), 583-593. https://doi.org/10.1017/S1355617713000076

US Census Bureau. (2017). Educational attainment in the United States: 2016. Retrieved 10 April 2017, from https://www.census.gov/data/tables/2016/demo/education-attainment/cps-detailed-tables.html

Van Laar, C. (2000). The paradox of low academic achievement but high self-esteem in African American students: An attributional account. Educational Psychology Review, 12(1), 33-61. https://doi.org/10.1023/A:1009032900261

Vispoel, W. P. (1995). Self-concept in artistic domains: An extension of the Shavelson, Hubner, and Stanton (1976) model. Journal of Educational Psychology, 87(1), 134-153. https://doi.org/10.1037/0022-0663.87.1.134

von Soest, T., Wichstrøm, L., \& Kvalem, I. L. (2016). The development of global and domain-specific selfesteem from Age 13 to 31. Journal of Personality and Social Psychology, 110(4), 592-608. https://doi.org/10.1037/pspp0000060

Voyer, D., \& Voyer, S. (2014). Gender differences in scholastic achievement: A meta-analysis. Psychological Bulletin, 140(4), 1174-1204. https://doi.org/10.1037/a0036620

Yerkes, R., \& Dodson, J. (1908). The relation of strength of stimulus to rapidity of habit formation. Journal of Comparative Neurology \& Psychology, 18(5), 459-482. https://doi.org/10.1002/cne.920180503 


\section{BIOGRAPHIES}

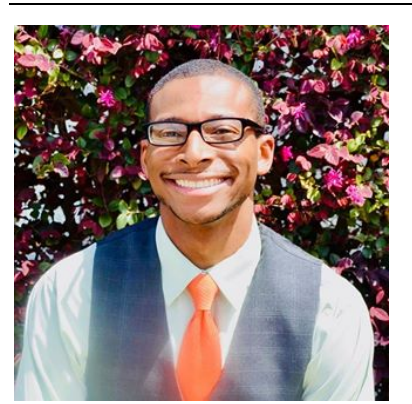

Novell E. Tani is an Assistant Professor of Psychology at Florida Agricultural \& Mechanical University (FAMU). He earned his B.S. in Psychology and Master's degree in Applied Social Sciences, with an emphasis on History, from FAMU. He holds an M.S. and Ph.D. in Development Psychology from the Florida State University (FSU). His research interests include teacher perceptions, teacher-student interactions, students' self-concept/self-efficacies, and micro- and macro -leveled factors that impact academic success. Dr. Tani has worked in various higher education settings before coming to FAMU. He has been awarded graduate directive status within FAMU's College of Sciences, Arts, and Humanities. As a faculty member within the Department of Psychology, he aids in the mentorship of undergraduate and graduate student research/theses surrounding the academic development of students of color.

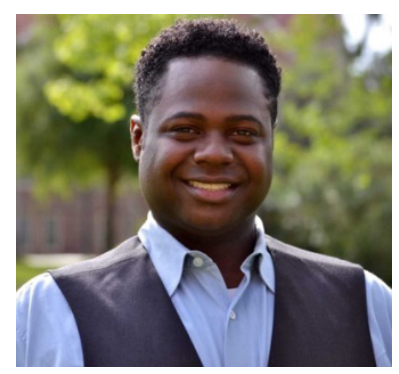

Akeem T. Ray earned his B.S. in Psychology from Florida State University. He earned a Master's Degree in Community Psychology from Florida Agricultural and Mechanical University (FAMU). Akeem Ray has held several positions at institutions of higher learning. His roles have included researcher, teaching assistant, departmental assistant, and guest lecturer. His research interests include student self-concepts, esteem and motivational levels concerning output, organizational psychology with a focus on diversity in the workplace, socialized gender norms and impacts on performance, and variants in cultural contexts that impact performance/production. 